\title{
Publisher Correction to: Multiple articles in Food Science and Biotechnology
}

\author{
The Publisher ${ }^{1}$
}

Published online: 12 June 2018

(C) The Korean Society of Food Science and Technology and Springer Science+Business Media B.V., part of Springer Nature 2018

\section{Correction to: Food Sci Biotechnol}

https://doi.org/10.1007/s10068-017-0270-4 https://doi.org/10.1007/s10068-018-0333-1 https://doi.org/10.1007/s10068-018-0336-y https://doi.org/10.1007/s10068-018-0338-9 https://doi.org/10.1007/s10068-018-0340-2 https://doi.org/10.1007/s10068-018-0342-0 https://doi.org/10.1007/s10068-018-0343-z https://doi.org/10.1007/s10068-018-0351-z https://doi.org/10.1007/s10068-018-0353-x https://doi.org/10.1007/s10068-018-0354-9 https://doi.org/10.1007/s10068-018-0357-6 https://doi.org/10.1007/s10068-018-0362-9 https://doi.org/10.1007/s10068-018-0365-6 https://doi.org/10.1007/s10068-018-0366-5
In the original version of these 14 articles the reference list was unfortunately not represented according to the journal's new bibliographical style, which should have been implemented from January 2018. The references should have been indicated by the Author Name and Year of Publication and the reference list should have been arranged as in the following pattern:

Journal article: Author(s). Article title. Journal title. Volume number: inclusive pages. Year in parentheses.

Books: Author(s) or editor(s). Title. Edition or volume. Publisher name, Place of publication. Number of cited pages or inclusive pages. Year in parentheses.

Chapter in book: Author(s) of the chapter. Chapter title. Volume (if relevant). Inclusive pages of the chapter. In: Title of the book. Author(s) or editor(s). Publisher name, Place of publication. Year in parentheses.

The original article can be found online at https://doi.org/10.1007/s10068-017-0270-4. https://doi.org/10.1007/s10068-018-0333-1 https://doi.org/10.1007/s10068-018-0336-y https://doi.org/10.1007/s10068-018-0338-9 https://doi.org/10.1007/s10068-018-0340-2 https://doi.org/10.1007/s10068-018-0342-0 https://doi.org/10.1007/s10068-018-0343-z https://doi.org/10.1007/s10068-018-0351-z https://doi.org/10.1007/s10068-018-0353-x https://doi.org/10.1007/s10068-018-0354-9 https://doi.org/10.1007/s10068-018-0357-6 https://doi.org/10.1007/s10068-018-0362-9 https://doi.org/10.1007/s10068-018-0365-6 https://doi.org/10.1007/s10068-018-0366-5

The Publisher

Singapore, Singapore 